Article

\title{
Increased Varietal Aroma Diversity of Marselan Wine by Mixed Fermentation with Indigenous Non-Saccharomyces Yeasts
}

\author{
Xiaomin Xi, Aili Xin, Yilin You, Weidong Huang and Jicheng Zhan * \\ Beijing Key Laboratory of Viticulture and Enology, College of Food Science and Nutritional Engineering, China \\ Agricultural University, Beijing 100083, China; xxm1113@cau.edu.cn (X.X.); xaljy68751807@163.com (A.X.); \\ yilinyou@cau.edu.cn (Y.Y.); huanggwd@263.net (W.H.) \\ * Correspondence: zhanjicheng@cau.edu.cn
}

Citation: Xi, X.; Xin, A.; You, Y.; Huang, W.; Zhan, J. Increased Varietal Aroma Diversity of Marselan Wine by Mixed Fermentation with Indigenous Non-Saccharomyces Yeasts.

Fermentation 2021, 7, 133.

https://doi.org/10.3390/

fermentation7030133

Academic Editor: Rosanna Tofalo

Received: 24 June 2021

Accepted: 22 July 2021

Published: 27 July 2021

Publisher's Note: MDPI stays neutral with regard to jurisdictional claims in published maps and institutional affiliations.

Copyright: (c) 2021 by the authors. Licensee MDPI, Basel, Switzerland. This article is an open access article distributed under the terms and conditions of the Creative Commons Attribution (CC BY) license (https:// creativecommons.org/licenses/by/ $4.0 /)$

\begin{abstract}
The common use of commercial yeasts usually leads to dull wine with similar aromas and tastes. Therefore, screening for novel indigenous yeasts to practice is a promising method. In this research, aroma discrepancies among six wine groups fermentated with indigenous yeasts were analyzed. Three Saccharomyces yeasts (FS36, HL12, YT28) and three matched non-Saccharomyces yeasts (FS31, HL9, YT2) were selected from typical Chinese vineyards. The basic oenological parameters, aroma compounds, and sensory evaluation were analyzed. The results showed that each indigenous Saccharomyces yeast had excellent fermentation capacity, and mixed-strain fermentation groups produced more glycerol, contributing to sweeter and rounder taste. The results from GC-MS, principal components analysis (PCA), and sensory evaluation highlighted that the HL mixed group kept the most content of Marselan varietal flavors such as calamenene and $\beta$-damascone hereby ameliorated the whole aroma quality. Our study also implied that the indigenous yeast from the same region as the grape variety seems more conducive to preserve the natural variety characteristics of grapes.
\end{abstract}

Keywords: marselan wine; aroma compounds; indigenous yeast strains; Saccharomyces; non-Saccharomyces

\section{Introduction}

A balanced and complex aroma is one of the most attractive factors that determine consumers' preference for wine, which also reflects the wine quality and value [1]. Yeasts are one of the most significant factors that impact the wine aroma profile by producing a large array of volatile compounds [2]. However, with the wide application of commercial Saccharomyces strains, inherent limitation gradually appears due to reducing the uniqueness and particularity of regional wine bouquets [3]. The current set of commercial S. cerevisiae strains and its derived hybrids is insufficient to provide novel properties to wine, stressing the need for new and improved strains for the industry [4]. Moreover, different yeast species and even different genotypes of yeasts displayed distinct wine aroma profiles [5]. The use of standard starter cultures, mainly applied to reduce the risk of spoilage and unpredictable changes of wine flavor, can ensure a balanced wine flavor, but it also causes a loss of characteristic aroma and flavor determinants. Therefore, this awareness opened new requirements to meet wine makers' demand for "special yeasts for special traits". Recently, the role of indigenous Saccharomyces yeast strains has gained much more attraction as a novel tool to convey regional characters to wine itself. Indeed, the application of a "locationspecific" starter culture highlighted the association between the profile of wine aromas and the geographical origin of the yeast used for the fermentation process $[3,6-8]$. There are plenty of yeast resources distributed widely in Chinese vineyards, requiring deeper research and proper application urgently. Therefore, using autochthonous Saccharomyces yeasts instead of commercial ones has been greatly encouraged in current winemaking due to their excellent adaptability for the local climate, soil, and micro-conditions and improve the aroma quality of wine by generating unique regional characters [9]. 
Usually, wine fermentations constitute complex microbial ecosystems, including Saccharomyces yeasts and non-Saccharomyces yeasts. The term "non-Saccharomyces yeasts" was used in the past to refer to a group of species with secondary relevance during the fermentation of grape musts to wine, considered even as spoilage organisms [10]. More recently, they are recognized for their beneficial role in improving the wine quality by producing some distinctive metabolites and are selected and screened for desired requirements [8]. Although most non-Saccharomyces yeasts are incapable of completing alcoholic fermentation due to low ethanol tolerance, they play a significant role in producing aroma compounds, such as esters, higher alcohols, acids, and monoterpenes [11]. The contributions to the wine aroma by non-Saccharomyces yeasts can occur through different mechanisms. The most important is probably the direct biosynthesis of volatile aroma compounds, and many of them have been identified. Some non-Saccharomyces yeasts produce certain glucosidase enzymes such as $\beta$-glucosidase or $\beta$-xylosidase that release volatile compounds from glycosidic precursors. Other metabolic products include terpenoids, esters, higher alcohols, acetaldehyde, organic acids, volatile fatty acids, carbonyl, and sulfur compounds. In addition, the application of non-Saccharomyces can also reduce the content of sulfur dioxide $\left(\mathrm{SO}_{2}\right)$ to lessen the hazards on human health and improve the content of total glycerol, which positively influences the wine taste by improving smoothness, sweetness, mouth-feel, and complexity [12]. In recent years, the inoculation of non-Saccharomyces yeasts as co-starters in wine production represents a promising winemaking method to ameliorate the wine aroma profiles. Besides the enhancement of wine aroma, they can also provide more essential functions, such as modulating the acidity, lowering the alcohol level, producing enzymes that optimize the winemaking process, such as clarification, filtration, and color extraction [13]. Numerous studies about co-fermentations of Saccharomyces yeasts with selected non-Saccharomyces yeasts in a controlled manner have proven to produce the wine with distinct aromatic profiles and higher complexity and quality of wine aromas, such as improving the content of glycerol, enhancing medium-chain fatty acid ethyl esters or producing higher contents of esters and $\beta$-damascenone $[7,14]$.

Our previous study has screened and selected a wide diversity in an extensive collection of both Saccharomyces yeasts and non-Saccharomyces yeasts from multiple regions in China, giving suitable support and a solid foundation to this study. Here, we used Marselan as material, a young but promising variety in China. Marselan (Vitis vinifera L.) is a hybrid cultivar of two famous grape varieties, Cabernet Sauvignon and Grenache [15], combining the finesse and high quality of Cabernet Sauvignon, disease resistance, and high yield of Grenache, which has the capacity to produce high qualified wine with deep color, elegant aromas, and potential for aging [16]. However, little is understood about the aromatic profile of Marselan must and how Chinese autochthonous Saccharomyces yeasts inoculated with non-Saccharomyces yeasts perform on Marselan. In our previous work, three indigenous Saccharomyces yeast strains (FS36, YT28, and HL12) and three corresponding indigenous non-Saccharomyces (FS31, YT2, and HL9) were isolated from Fangshan (Beijing), Yantai (Shandong province), and Huailai (Hebei province), respectively. Therefore, the main objectives of the study were to firstly identify the characteristic aroma compounds of Marselan must by GC-MS; then to analyze the aroma profiles of Marselan wine fermented with autochthonous Saccharomyces yeasts and non-Saccharomyces yeasts by pure and mixed methods; and to evaluate the sensory attributes of different Marselan wine through panelists sensory evaluation, PCA and partial least squares regression (PLSR).

\section{Materials and Methods}

\subsection{Marselan Must Samples}

There are four Marselan must samples (China). Three were from the 2018 vintage, from Huailai (Hebei), Fangshan (Beijing), and Yantai (Shandong), respectively, shorted for 2018 HL, 2018 FS, and 2018 YT. Another sample was from 2017 vintage and Huailai, shorted for $2017 \mathrm{HL}$. 


\subsection{Yeast Strains}

The detailed information about yeast strains was listed in Table 1, all selected and identified in our lab previously. Six autochthonous strains, including three $S$. cerevisiae strains (FS36, YT28, and HL12) and three matched non-Saccharomyces strains (FS31, YT2, and HL9). The strains were stored at $-80^{\circ} \mathrm{C}$ in yeast extract peptone dextrose medium (YPD, yeast extract $10 \mathrm{~g} / \mathrm{L}$, peptone $20 \mathrm{~g} / \mathrm{L}$, and glucose $20 \mathrm{~g} / \mathrm{L}$ ) with the addition of glycerol (20\% v/v final concentration). Among them, HL12, YT28, and FS31 were deposited in China General Microbiological Culture Collection Center (CGMCC), and the numbers were No. 20632, No. 20633, and No. 20636, respectively.

Table 1. The information of yeast strains.

\begin{tabular}{cccc}
\hline Name & Region & Species & Property \\
\hline FS36 & Fanghshan, Beijing & Saccharomyces cerevisiae & Saccharomyces \\
FS31 & Fanghshan, Beijing & Kazachstania exigua & Non-Saccharomyces \\
YT28 & Yantai, Shandong & Saccharomyces cerevisiae & Saccharomyces \\
YT2 & Yantai, Shandong & Candida glabrata & Non-Saccharomyces \\
HL12 & Huailai, Hebei & Saccharomyces cerevisiae & Saccharomyces \\
HL9 & Huailai, Hebei & Hanseniaspora opuntiae & Non-Saccharomyces \\
\hline
\end{tabular}

\subsection{Chemicals}

Sulfuric acid, sulfuric acid, ammonia, sodium hydroxide, peptone, and hydrochloric acid were purchased from Beijing Chemical Reagent Factory (Beijing, China). Methanol and acetonitrile were purchased from Merck, Germany. Standards (glucose, fructose, glycerol, ethanol, citric acid, tartaric acid, pyruvic acid, malic acid, succinic acid, acetic acid, and ascorbic acid) were all purchased from Sigma-Aldrich, China Co. (St. Louis, MI, USA) with at least $97 \%$ purity.

\subsection{HS-SPME-GC-MS Analysis}

The volatile compounds of Marselan wine samples were extracted using the Head Space Solid Phase Microextraction (HS-SPME) method as described [17]. For each analysis, $2.5 \mathrm{~g}$ of sodium chloride $(\mathrm{NaCl})$ and $10 \mu \mathrm{L}$ of 2-octanol (internal standard) were added to $5 \mathrm{~mL}$ of must sample into a $20 \mathrm{~mL}$ headspace screw vial. Helium $(\mathrm{He})$ was the carrier gas at a constant flow rate of $1 \mathrm{~mL} / \mathrm{min}$. The SPME fiber was inserted through the needle and exposed into the headspace of the vial to adsorb volatile compounds at $45^{\circ} \mathrm{C}$ for $50 \mathrm{~min}$ and then immediately injected into the gas chromatography injection port at $250{ }^{\circ} \mathrm{C}$ for $2.5 \mathrm{~min}$ to desorb volatile compounds; afterward, GC-MS separation, analysis, and identification was performed.

The volatile compounds from the samples were analyzed by Gas Chromatography and Mass Spectrometry (GC-MS) according to a previous description with some modification [18]. GCMS-QP2010 Ultra (SHIMADZU, Kyoto, Japan) was used with a DB-Wax capillary column (30 mm length $\times 0.25 \mathrm{~mm}$ i.d. $\times 0.25 \mu \mathrm{m}$ film thickness), and splitless injection mode was adopted. High purity helium, as a carrier gas, was used at a constant flow rate of $1 \mathrm{~mL} / \mathrm{min}$. The gas chromatographic oven was set at $50{ }^{\circ} \mathrm{C}$ for $5 \mathrm{~min}$, increased until $230{ }^{\circ} \mathrm{C}$ at a rate of $5{ }^{\circ} \mathrm{C} / \mathrm{min}$, and finally maintained for $30 \mathrm{~min}$. Other conditions included an interface temperature of $250^{\circ} \mathrm{C}$, an emission current of $100 \mu \mathrm{A}$, and mass spectra were obtained at $70 \mathrm{eV}$ in the electron ionization $+(\mathrm{EI}+)$ mode. The mass spectral identification of volatile compounds in the samples was carried out by comparing to the National Institute of Standards and Technology (NIST) 2014 and Wiley 8.0 database. Qualitative analysis of mass spectral data was verified by comparing the retention indices and mass spectra of identified compounds. The qualitative aroma components were qualitatively determined by NIST2011 and the Demo library. Volatile compounds extraction $(\mu \mathrm{g} / \mathrm{L})=($ peak area of volatile compounds / peak area of internal standard $\times$ mass of internal standard) $/$ mass of sample. 


\subsection{Fermentation Methods}

The 2017 HL Marselan grape must was used as material for all trails. The frozen grape juice was placed at $4{ }^{\circ} \mathrm{C}$, centrifuged at high speed in $50 \mathrm{~mL}$ tubes. The supernatant was filtered with 0.65 then $0.45 \mu \mathrm{m}$ filters to obtain the sterile grape juice. Yeasts were inoculated at $28{ }^{\circ} \mathrm{C}$ for 48 hours until the amount was $10^{7} \mathrm{CFU} / \mathrm{mL}$. A total of $300 \mathrm{~mL}$ sterile grape juice was measured. For single-strain fermentation groups, the pre-cultured Saccharomyce yeasts (FS36, YT28, and HL12) were inoculated. For mixed-strain fermentation groups, non-Saccharomyce yeasts (FS31, YT2, and HL9) were inoculated (with the ratio of 1\%). Three parallels for each group were set. After the inoculation, all samples were placed in the incubator at $20^{\circ} \mathrm{C}$. On the $4^{\text {th }}$ day, the pre-cultured Saccharomyce yeasts (FS36, YT28, and HL12) were added to the corresponding mixed groups (with the ratio of $1 \%$ ). On the 0th, 2, 4, 6, 10, 14, and 19 days, the wine bottles were fully shaken, samples were taken to detect the yeast number, Brix, $\mathrm{pH}$, residual sugar, acid, ethanol, glycerol, and volatile aroma components. When the yeast began to decline and the Brix value kept stable, the fermentation was terminated. The supernatant of wine was taken and stored at $4{ }^{\circ} \mathrm{C}$. All the trials were demonstrated in Table 2: (1) single fermentation with FS36 (short for FS36); (2) mixed fermentation of FS36 and FS31 (short for FS mixed); (3) single fermentation with YT28 (short for YT28); (4) mixed fermentation of YT28 and YT2 (short for YT mixed); (5) single fermentation with HL12 (short for HL12); and (6) mixed fermentation of HL12 and HL9 (short for HL mixed).

Table 2. The method of fermentation trails.

\begin{tabular}{ccc}
\hline Fermentation Trails & Yeasts & Method \\
\hline FS36 & FS36 alone & $/$ \\
FS Mixed & FS31 + FS36 & FS36 was inoculated on 4th day \\
YT28 & YT28 alone & / \\
YT Mixed & YT2 + YT28 & YT28 was inoculated on 4th day \\
HL12 & HL12 alone & HL12 was inoculated on 4th day \\
HL Mixed & HL9 + HL12 & HL12
\end{tabular}

\subsection{Sensory Analysis}

Wine aroma was evaluated in triplicates by a tasting panel consisting of four females and four males trained with a 54-aroma kit (Le Nez du Vin ${ }^{\circledR}$, France) for three weeks. During the training, the performances were evaluated by aroma sense test every five days until their identification accuracy for each aroma reached above $95 \%$. The analysis was conducted in a tasting room at $23^{\circ} \mathrm{C}$. Approximately $30 \mathrm{~mL}$ of wine $\left(15^{\circ} \mathrm{C}\right)$ was held in a black wine glass. Throughout the wine sensory analysis, the samples were presented in random order. The interval between the two samples was $5 \mathrm{~min}$. The panelists evaluated wine aroma according to the following procedure: they smelled the aroma of wine sample for approximately 5-8 s, then shook the wine to smell the aroma for 5-10 s, defined aromas, and scored. The sensory descriptors were alcohol, floral, citrus, stone fruits, berries, dry fruits, herbs, and fermentative aromas. The samples were quantitatively measured on a 5 point interval scale to grade the intensity (1-very weak; 2-weak; 3-medium; 4-intense; 5-very intense).

\subsection{Detection of Physicochemical Parameters}

Glucose, fructose, ethanol, glycerol were all detected by high-performance liquid chromatography (HPLC) [19]. The chromatographic conditions: sugar analysis column Aminex HPX-87H $(300 \times 7.8 \mathrm{~mm})$, column temperature $55^{\circ} \mathrm{C}$, differential detector (RID, Waters-2414), internal temperature $40{ }^{\circ} \mathrm{C}, 0.005 \mathrm{~mol} / \mathrm{L} \mathrm{H}_{2} \mathrm{SO}_{4}$, injection volume $10 \mu \mathrm{L}$, flow rate $0.5 \mathrm{~mL} / \mathrm{min}$ isocratic elution, qualitative by retention time, and quantitative peak area. $\mathrm{pH}$ and Brix were detected by $\mathrm{pH}$ meter and Brix meter. Based on our previous method, the flow rate was modified to $0.8 \mathrm{~mL} / \mathrm{min}$, RP-HPLC was used to detect eight organic acids. The chromatographic conditions are: Tech Mate ST-C $(4.6 \times 250 \mathrm{~mm}, 5 \mu \mathrm{m})$, column 
temperature $25^{\circ} \mathrm{C}$, ultraviolet detector (PAD, Waters-2996), detection wavelength $210 \mathrm{~nm}$, mobile phase: ammonium dihydrogen phosphate $\left(\mathrm{NH}_{4} \mathrm{H}_{2} \mathrm{PO}_{4}\right) 40 \mathrm{mmol} / \mathrm{L}(4.6 \mathrm{~g} / \mathrm{L})$, $\mathrm{H}_{3} \mathrm{PO}_{4}$ adjusted $\mathrm{pH}$ to 2.5 , injection volume $10 \mu \mathrm{L}$, flow rate $0.8 \mathrm{~mL} / \mathrm{min}$, isocratic elution, qualitative retention time, and peak area quantification.

\subsection{Statistical Analysis}

Analysis of variance (ANOVA, least significant difference method at a significance level of $p \leq 0.05$ ) was used to evaluate differences between the samples by the SPSS 19.0 software (SPSS Inc., Chicago, IL, USA). Principal component analysis (PCA) was carried out by $\mathrm{R}$ studio to visualize the differences between wines fermented by different strains and inoculation methods. PLSR was applied to identify the contribution of the key aroma compounds to the flavor characteristics of wine samples, and it was conducted using Unscrambler $X$ version (Camo, Trondheim, Norway). All the figures were carried out by Graphpad Prism 8 (GraphPad Software Inc., San Diego, CA, USA).

\section{Results}

\subsection{Aroma Compounds of Marselan Must Detected by GC-MS}

Previously, it has been identified that some key aromas such as $\beta$-damascenone, eugenol, and 2,3-butanedione in Marselan wine [20]. However, little research was found to investigate the characteristic aromas of Marselan must. There is no doubt that it is very essential to figure out the features of a certain variety before making a type of wine. Therefore, firstly we carried out the experiments to identify the characteristic varietal aromas in Marselan must, and those aromas could represent and distinguish the various properties. Table 3 showed the total volatile compounds that were identified and quantified by GC-MS with HS-SPME in four Marselan must samples. There were 30 aroma compounds detected in 2017 HL, 39 in 2018 FS, 42 in 2018 YT, and 41 in 2018 HL Marselan must, of which 20 aromas were detected in common. The threshold of $\mathrm{C}_{13}$-norisoprenoids and terpenes in grape fruits is very low; however, they have great influence on grape aroma formation. The results showed that $\mathrm{C}_{13}$-norisoprenoid compounds mainly included violine, $\beta$-damascenone, and calamenene; terpenes mainly included linalool, $\alpha$-terpene, 4-terpineol, $\beta$-myrcene, and semenene. The aroma compounds detected in all groups included calamenene, $\beta$-damascenone, phenylethyl alcohol, ethyl octoate, ethyl hexanoate, ethyl benzoate, ethyl laurate, n-hexanal, benzaldehyde, furfural, ceremonene, 2,4-di-tertbutylphenol, etc. Furthermore, calamenene, $\beta$-damascenone, n-hexanal, furfural, and ceremonene were significantly different among the samples. Moreover, $\alpha$-ionone was only detected in 2018 YT, and linalool was only found in 2018 HL. 2-Hexenal with $27 \%$ relative content only appeared in 2018 FS, accounting for a relatively high proportion. Hexanal, nonanal, and semenene could be detected in all samples. The relative content of 1-hexanol in 2018 YT and 2018 HL reached more than 60\%; however, it was not detected in the rest samples; the relative content of n-hexanal in $2017 \mathrm{HL}$ was the most abundant, accounting for $46.5 \%$. All these results indicated that different must samples had verified aromatic profiles. To compare all the samples, the relative content of characteristic aroma compounds was showed in Figure S1. There were seven characteristic aromas as summarized: phenethyl alcohol, ethyl octoate, ethyl caproate, calamenene, $\beta$-damascenone, benzaldehyde, and 2,4di-tert-butylphenol. In 2017 HL and $2018 \mathrm{HL}$, except for calamenene, all aroma compounds had significant differences. On the whole, except for $\beta$-damastonone that $2018 \mathrm{HL}$ produced most, 2017 HL had more levels of aroma compounds than 2018 HL. Comparing the samples from 2018, significant differences were observed in all aroma compounds apart from $\beta$-damastonone. Grape aroma is principally influenced by sugar accumulation and transformation [21], which might explain the variation of the aroma profiles. 
Table 3. The average peak area and relative peak area (RPA) of volatile aroma compounds of Marselan must.

\begin{tabular}{|c|c|c|c|c|c|c|c|c|}
\hline & $2017 \mathrm{HL}$ & & 2018 FS & & $2018 \mathrm{YT}$ & & $2018 \mathrm{HL}$ & \\
\hline Aroma Compound & Peak Area * $10^{6}$ & RPA \% & Peak Area * $10^{6}$ & RPA\% & Peak Area * $10^{6}$ & RPA \% & Peak Area * $10^{6}$ & RPA \% \\
\hline \multicolumn{9}{|l|}{ C13-Norisoprenoids } \\
\hline Violine & N.D. & 0.00 & $5.42 \pm 0.12^{\mathrm{a}}$ & 1.10 & $2.35 \pm 0.09^{b}$ & 0.24 & $2.17 \pm 0.01^{b}$ & 0.24 \\
\hline Calamenene & $1.37 \pm 0.33^{\mathrm{d}}$ & 0.42 & $3.45 \pm 0.10^{\mathrm{a}}$ & 0.72 & $2.28 \pm 0.39^{b}$ & 0.23 & $1.77 \pm 0.22^{c}$ & 0.20 \\
\hline$\beta$-Damascone & $18.35 \pm 0.42^{\mathrm{d}}$ & 5.60 & $32.82 \pm 1.01^{\mathrm{a}}$ & 6.83 & $30.69 \pm 0.59^{b}$ & 3.16 & $29.29 \pm 0.72^{c}$ & 3.25 \\
\hline \multicolumn{9}{|l|}{ Terpenes } \\
\hline Linalol & N.D. & 0.00 & N.D. & 0.00 & N.D. & 0.00 & $0.53 \pm 0.01$ & 0.06 \\
\hline 4-terpineol & N.D. & 0.00 & N.D. & 0.00 & N.D. & 0.00 & $0.57 \pm 0.03$ & 0.06 \\
\hline$\alpha$-terpene & N.D. & 0.00 & N.D. & 0.00 & $0.91 \pm 0.01$ & 0.09 & N.D. & 0.00 \\
\hline$\beta$-myrcene & N.D. & 0.00 & N.D. & 0.00 & N.D. & 0.00 & $2.81 \pm 0.13$ & 0.31 \\
\hline $\begin{array}{l}\text { Semenene } \\
\text { Alcohols }\end{array}$ & $1.65 \pm 0.11^{\mathrm{c}}$ & 0.50 & $2.35 \pm 0.30^{b}$ & 0.49 & $2.40 \pm 0.14^{b}$ & 0.25 & $3.34 \pm 0.14^{\mathrm{a}}$ & 0.37 \\
\hline Phenylethyl alcohol & $4.46 \pm 0.97^{\mathrm{a}}$ & 1.36 & $2.44 \pm 0.26^{\mathrm{ab}}$ & 0.51 & $1.40 \pm 0.10^{b}$ & 0.14 & $1.19 \pm 0.15^{b}$ & 0.13 \\
\hline 1-hexanol & N.D. & 0.00 & N.D. & 0.00 & $659.27 \pm 2.14^{\mathrm{a}}$ & 67.80 & $555.95 \pm 3.67^{b}$ & 61.70 \\
\hline $\begin{array}{l}\text { 1-hexene-3-ol } \\
\text { Esters }\end{array}$ & N.D. & 0.00 & N.D. & 0.00 & N.D. & 0.00 & $6.59 \pm 0.33$ & 0.73 \\
\hline Hexyl acetate & N.D. & 0.00 & N.D. & 0.00 & $4.45 \pm 0.12^{\mathrm{a}}$ & 0.37 & $2.48 \pm 0.04^{\mathrm{a}}$ & 0.28 \\
\hline Ethyl octoate & $1.50 \pm 0.28^{a}$ & 0.31 & $0.63 \pm 0.01^{\mathrm{a}}$ & 0.13 & $0.40 \pm 0.06^{\mathrm{a}}$ & 0.04 & $0.24 \pm 0.00^{\mathrm{a}}$ & 0.03 \\
\hline Phenethyl acetate & $1.42 \pm 0.02$ & 0.43 & N.D. & 0.00 & N.D. & 0.00 & N.D. & 0.00 \\
\hline Ethyl benzoate & $0.52 \pm 0.07^{\mathrm{a}}$ & 0.16 & $0.50 \pm 0.07^{\mathrm{a}}$ & 0.10 & $0.34 \pm 0.05^{\mathrm{a}}$ & 0.03 & $0.28 \pm 0.01^{\mathrm{a}}$ & 0.03 \\
\hline Ethyl hexanoate & $4.33 \pm 0.21^{\mathrm{a}}$ & 0.99 & $0.82 \pm 0.19^{\mathrm{a}}$ & 0.17 & $0.50 \pm 0.01^{\mathrm{a}}$ & 0.05 & $0.53 \pm 0.09^{\mathrm{a}}$ & 0.06 \\
\hline Ethyl phthalate & N.D. & 0.00 & $0.14 \pm 0.00^{\mathrm{a}}$ & 0.03 & $0.07 \pm 0.00^{b}$ & 0.01 & N.D. & 0.00 \\
\hline Ethyl myristate & $1.88 \pm 0.83^{a}$ & 0.57 & $0.28 \pm 0.05^{\mathrm{a}}$ & 0.06 & $0.09 \pm 0.00^{\mathrm{a}}$ & 0.01 & N.D. & 0.00 \\
\hline Ethyl palmitate & $1.85 \pm 0.02^{\mathrm{a}}$ & 0.56 & $0.33 \pm 0.11^{b}$ & 0.07 & $0.14 \pm 0.02^{\mathrm{a}}$ & 0.01 & N.D. & 0.00 \\
\hline $\begin{array}{l}\text { Ethyl laurate } \\
\text { Others }\end{array}$ & $5.93 \pm 0.31^{\mathrm{a}}$ & 1.81 & $1.56 \pm 0.37^{\mathrm{a}}$ & 0.32 & $1.11 \pm 0.01^{\mathrm{a}}$ & 0.11 & $0.36 \pm 0.00^{a}$ & 0.04 \\
\hline n-hexanal & $152.28 \pm 2.54^{\mathrm{a}}$ & 46.50 & $81.57 \pm 0.06^{b}$ & 17.00 & $53.60 \pm 1.25^{\mathrm{c}}$ & 5.51 & $94.70 \pm 0.22^{b}$ & 10.50 \\
\hline 2-hexenal & N.D. & 0.00 & $129.77 \pm 2.34$ & 27.00 & N.D. & 0.00 & N.D. & 0.00 \\
\hline Benzaldehyde & $6.01 \pm 0.56^{b}$ & 1.83 & $15.65 \pm 0.22^{a}$ & 3.26 & $14.02 \pm 0.57 \mathrm{ab}$ & 1.44 & $2.73 \pm 0.03^{b}$ & 0.30 \\
\hline Nonanal & $4.17 \pm 0.03^{\mathrm{a}}$ & 0.97 & $1.77 \pm 0.03^{b}$ & 0.37 & $1.16 \pm 0.16^{\mathrm{c}}$ & 0.12 & $1.00 \pm 0.00^{c}$ & 0.11 \\
\hline 2-decanone & N.D. & 0.00 & $0.93 \pm 0.01^{\mathrm{a}}$ & 0.19 & $1.06 \pm 0.05^{\mathrm{a}}$ & 0.11 & $1.02 \pm 0.00^{\mathrm{a}}$ & 0.11 \\
\hline 2,4-di-tert-butylphenol & $30.08 \pm 0.37^{a}$ & 9.18 & $13.41 \pm 0.07^{b}$ & 2.79 & $10.34 \pm 0.05^{b}$ & 1.06 & $10.17 \pm 1.20^{b}$ & 1.13 \\
\hline
\end{tabular}

N.D. means no detection. Different letters indicate the significant differences at $p<0.05$.

\subsection{Basic Parameters of Marselan Wine}

The whole fermentation process was monitored, and the physiochemical parameters (alcohol, glycerol, glucose, fructose, and Brix) were detected (Table S1 and Figure 1). On the whole, the fermentation speed of single-strain groups (FS36, YT28, and HL12) was significantly faster than mixed-strain groups (FS mixed, YT mixed, and HL mixed), which was in agreement with numerous authors [8,22-24]. Among them, FS36 was the fastest, followed by HL12 and YT28, implying that FS36 had the best fermentation ability. The mixed-strain groups began to ferment rapidly after sequentially inoculated the Saccharomyces yeast strains on the 4 th day. On the 19 th day, the Brix value of FS36, YT28, and HL12 was 7.7, 7.5, and 7.3, respectively; FS mixed, YT mixed, and HL mixed was 8.0, 7.8, and 7.7, respectively. All groups reached basically the same level and remained stable, indicating that all these Saccharomyces yeasts were well capable of completing alcoholic fermentation, and non-Saccharomyces did not hinder the process.

During the fermentation process, the use of glucose is usually superior to fructose [22], which is consistent with our results. Single-strain groups consumed glucose faster, and the final content was less than $2 \mathrm{~g} / \mathrm{L}$ on the 14th day. Mixed-strain groups used glucose from the 4 th day and completed it on the 19th day. Finally, the residual glucose in all groups was about $1 \mathrm{~g} / \mathrm{L}$. It should be noticed that the difference in fructose consumption rate was minor than glucose. FS36 metabolized fructose fastest, and YT mixed was the slowest. HL mixed and YT mixed groups had the maximum residual fructose, which was 0.81 and $2.92 \mathrm{~g} / \mathrm{L}$, separately. Interestingly, no matter in glucose or fructose consumption, the speed rank was the same (FS36 > HL12 > YT28). Figure 1C exhibited that FS36 produced the most glycerol as well as with the fastest speed. Compared with mixed-strain groups, single-strain groups produced glycerol at a higher rate. In contrast, the mixed-strain groups (FS mixed and YT mixed) yielded much more glycerol in the end. Glycerol is a by-product of yeast metabolism during wine fermentation that had been previously discovered that mixed fermentation with non-Saccharomyces provides more glycerol, offering wine richer sweety and round tastes $[7,8]$. Single-strain groups produced alcohol faster; however, the final 
alcohol volume tended to be approximative, suggesting that the non-Saccharomyces applied in the study did not block the fermentation process because some research pointed that the addition of non-Saccharomyces could spoilage the alcoholic fermentation [23]. These results presented that all the selected Saccharomyces yeast strains have excellent fermentation property and all chemical parameters belonged to a normal range, thus providing a solid foundation for our further analysis.
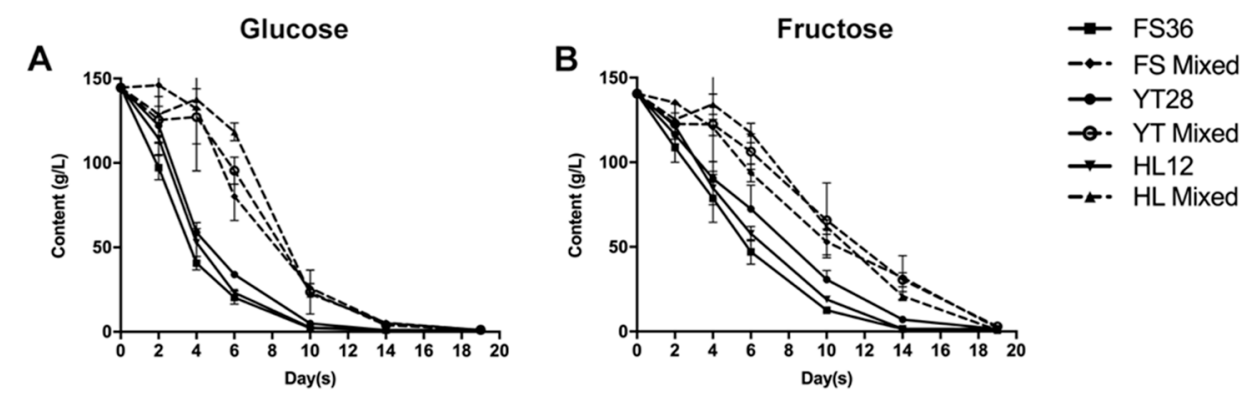

Glycerol


Figure 1. The basic parameters of six Marselan wines during fermentation.

\subsection{Identification of Aroma Compounds in Marselan Wine by GC-MS}

A total set of 53 aroma compounds were detected in FS36, 48 in YT28, 46 in HL12, 48 in FS mixed, 47 in the YT mixed, and 45 in the HL mixed, respectively. The main classes of volatile compounds were consistent with those analyzed by Lyu [24]. The results of quantitative GC-MS analysis for the aroma compounds were listed in Table 4 and summarized in Table S2.

Esters, including acetate esters and ethyl esters, are closely related to floral and fruity attributes formed by the esterification of fatty acids [25]. A total of 27 kinds of esters were detected, making them the most numerous groups in all aroma compounds. A total of 26 kinds of esters were detected in FS36, YT28, HL12 mixed, and FS mixed; a total of 27 and 25 kinds of esters were detected in YT mixed and HL mixed. Among them, ethyl decanoate was the single most abundant ester in all samples, with a significant difference between YT28 and YT mixed, giving fruity and pleasant floral flavors to the wine. Ethyl 9-decanoate ranked second, was less in HL groups $(8.76 \%$ of single group and $7.73 \%$ of mixed group), but had above $16 \%$ relative content in the other groups. The content of ethyl octoate ranked third and was highest distributed in YT28, also accounting for 5\% to 8\% among all groups. Importantly, ethyl octoate offers a pleasant flower, fruit flavors such as apricot, pineapple, pear, and creamy mushroom with a threshold of only $0.01 \mathrm{mg} / \mathrm{L}$, giving critical impacts on aroma profile [26]. Compared with grape must, the content of ethyl laurate was significantly increased as fermentation process. FS36 and FS mixed produced the most content of ethyl laurate, followed by YT and HL. Compared with the Marselan must samples, the number of esters in wine was remarkably increased, indicating that yeast biosynthesis is the main synthetic way to produce esters during fermentation. 
Table 4. The average peak area of volatile aroma compounds of Marselan wine.

\begin{tabular}{|c|c|c|c|c|c|c|}
\hline & FS36 & YT28 & HL12 & FS Mixed & YT Mixed & HL Mixed \\
\hline Aroma Compound & Peak Area * $10^{6}$ & Peak Area * $10^{6}$ & Peak Area $* 10^{6}$ & Peak Area $* 10^{6}$ & Peak Area $* 10^{6}$ & Peak Area $* 10^{6}$ \\
\hline \multicolumn{7}{|l|}{ Norisoprenes } \\
\hline Calamenene & N.D. & N.D. & N.D. & N.D. & $1.17 \pm 0.01^{b}$ & $4.42 \pm 0.03^{\mathrm{a}}$ \\
\hline $\begin{array}{c}\beta \text {-Damascone } \\
\text { Alcohols }\end{array}$ & $2.60 \pm 0.20^{c}$ & $2.20 \pm 0.09^{d}$ & $3.03 \pm 0.15^{b}$ & $3.18 \pm 0.08^{a b}$ & $2.77 \pm 0.06^{\mathrm{c}}$ & $3.34 \pm 0.18^{a}$ \\
\hline Phenethyl alcohol & $284.27 \pm 3.75^{\mathrm{de}}$ & $371.74 \pm 1.97^{c}$ & $287.04 \pm 0.91$ de & $249.47 \pm 0.89$ e & $462.46 \pm 0.29^{a}$ & $323.63 \pm 1.02^{\mathrm{d}}$ \\
\hline Decyl alcohol & $2.07 \pm 0.07^{\mathrm{a}}$ & N.D. & $1.84 \pm 0.07^{\mathrm{b}}$ & N.D. & N.D. & N.D. \\
\hline Trans $\beta$-farnesol & $6.82 \pm 0.70^{\mathrm{a}}$ & $3.68 \pm 0.59^{b}$ & N.D. & $1.33 \pm 0.16^{c}$ & N.D. & $1.06 \pm 0.11^{\mathrm{d}}$ \\
\hline$\beta$-bisabolol & $4.02 \pm 0.81^{\mathrm{a}}$ & $1.28 \pm 0.23^{b}$ & $1.04 \pm 0.21^{b}$ & $2.02 \pm 0.11 \mathrm{ab}$ & $1.32 \pm 0.27^{b}$ & $1.40 \pm 0.21^{b}$ \\
\hline $\begin{array}{l}\text { Cis- } \alpha \text {-bisabolol } \\
\text { Esters }\end{array}$ & \multicolumn{5}{|c|}{ Esters } & $0.66 \pm 0.32^{\mathrm{a}}$ \\
\hline Ethyl hexanoate & $33.62 \pm 6.22^{b}$ & $37.08 \pm 2.62^{b}$ & $67.43 \pm 1.20^{a}$ & $40.74 \pm 0.76^{b}$ & $43.93 \pm 0.94^{b}$ & $63.21 \pm 1.39^{a}$ \\
\hline Hexyl acetate & N.D. & N.D. & N.D. & $2.45 \pm 0.44^{\mathrm{a}}$ & $2.55 \pm 0.87^{a}$ & $3.40 \pm 0.30^{\mathrm{a}}$ \\
\hline Ethyl octanoate & $771.21 \pm 5.13^{b}$ & $792.82 \pm 31.12^{b}$ & $996.70 \pm 8.57^{\mathrm{a}}$ & $732.79 \pm 14.52^{b}$ & $766.20 \pm 1.45^{b}$ & $777.31 \pm 7.79^{b}$ \\
\hline 7-Ethyl caprylate & $3.38 \pm 0.78^{\mathrm{b}}$ & $3.11 \pm 0.05^{\mathrm{b}}$ & $3.00 \pm 0.85^{b}$ & $2.52 \pm 0.56^{b}$ & $5.70 \pm 0.82^{\mathrm{a}}$ & $4.56 \pm 0.13^{\mathrm{ab}}$ \\
\hline 3-Methylbutyl octanoate & $3.24 \pm 0.79^{b}$ & $7.29 \pm 1.42^{\mathrm{a}}$ & $6.27 \pm 0.18^{a b}$ & $4.95 \pm 0.36^{\mathrm{ab}}$ & $6.20 \pm 1.42^{\mathrm{ab}}$ & $3.87 \pm 0.40^{\mathrm{b}}$ \\
\hline Ethyl benzoate & $0.72 \pm 0.13^{b}$ & $1.31 \pm 0.15^{\mathrm{ab}}$ & $3.42 \pm 0.31^{\mathrm{a}}$ & $1.07 \pm 0.23^{\mathrm{ab}}$ & $1.88 \pm 0.38^{a b}$ & $1.68 \pm 0.44^{\mathrm{ab}}$ \\
\hline Diethyl succinate & $2.07 \pm 0.12^{b c}$ & $1.83 \pm 0.34^{b c}$ & $3.06 \pm 0.06^{\mathrm{ab}}$ & $1.27 \pm 0.20^{c}$ & $2.34 \pm 0.44^{b}$ & $3.56 \pm 0.09^{a}$ \\
\hline Phenethyl acetate & $39.51 \pm 6.42^{c}$ & $51.78 \pm 1.70 \mathrm{bc}$ & $40.29 \pm 3.12^{c}$ & $43.98 \pm 0.75^{c}$ & $72.26 \pm 1.03^{a}$ & $56.46 \pm 0.56^{b}$ \\
\hline 2-Methyl propyl caprylate & $2.03 \pm 0.08^{\mathrm{a}}$ & $2.03 \pm 0.12^{\mathrm{a}}$ & $2.05 \pm 0.15^{\mathrm{a}}$ & $1.81 \pm 0.40^{\mathrm{a}}$ & $2.04 \pm 0.14^{\mathrm{a}}$ & $2.49 \pm 0.06^{\mathrm{a}}$ \\
\hline Ethyl decanoate & $3493.96 \pm 43.58^{a}$ & $3455.40 \pm 23.77^{a}$ & $3154.25 \pm 24.12^{\mathrm{ab}}$ & $3051.76 \pm 7.57^{\mathrm{ab}}$ & $2577.69 \pm 19.87^{b}$ & $2520.97 \pm 15.39^{b}$ \\
\hline Ethyl 9-decanoate & $2670.03 \pm 28.46^{a}$ & $2093.40 \pm 18.67^{b}$ & $990.66 \pm 7.37^{c}$ & $1992.78 \pm 17.91^{b}$ & $2261.45 \pm 3.09 \mathrm{ab}$ & $850.23 \pm 8.75^{\mathrm{c}}$ \\
\hline Ethyl oleate & $23.73 \pm 1.82^{\mathrm{a}}$ & $6.22 \pm 0.54^{b c}$ & $4.82 \pm 1.38^{\mathrm{bc}}$ & $11.11 \pm 0.81^{\mathrm{b}}$ & $3.21 \pm 1.26^{c}$ & $3.39 \pm 0.25^{c}$ \\
\hline Ethyl propionate & N.D. & N.D. & N.D. & $11.96 \pm 1.20^{a}$ & $3.28 \pm 1.26^{\mathrm{a}}$ & $3.83 \pm 1.40^{\mathrm{a}}$ \\
\hline Trans ethyl 4-decanoate & $16.98 \pm 3.64^{\mathrm{a}}$ & $16.65 \pm 2.52^{\mathrm{a}}$ & $6.70 \pm 1.07^{b}$ & $11.88 \pm 0.96^{\mathrm{ab}}$ & $4.10 \pm 1.61^{b}$ & N.D. \\
\hline Isoamyl caprylate & $52.56 \pm 6.71^{a}$ & $48.57 \pm 1.07^{\mathrm{a}}$ & N.D. & $42.43 \pm 2.70^{a}$ & N.D. & N.D. \\
\hline Propyl decanoate & $4.91 \pm 0.22^{\mathrm{a}}$ & $2.91 \pm 0.48^{b}$ & $2.08 \pm 0.29^{c}$ & $4.21 \pm 2.74^{\mathrm{a}}$ & $2.35 \pm 0.80 \mathrm{bc}$ & $1.67 \pm 0.75^{c}$ \\
\hline Ethyl undecanoate & $2.48 \pm 0.46^{\mathrm{ab}}$ & $2.29 \pm 0.60^{b}$ & $0.97 \pm 0.02^{c}$ & $2.90 \pm 0.34^{\mathrm{a}}$ & $2.03 \pm 0.09^{b}$ & $0.93 \pm 0.14^{c}$ \\
\hline Ethyl laurate & $65.84 \pm 0.96^{\mathrm{ab}}$ & $51.71 \pm 0.08^{b}$ & $33.36 \pm 0.84^{c}$ & $71.22 \pm 0.10^{a}$ & $41.28 \pm 0.15^{\mathrm{bc}}$ & $21.37 \pm 0.23^{c}$ \\
\hline $\begin{array}{l}\text { Ethyl palmitate } \\
\text { Others }\end{array}$ & \multicolumn{5}{|c|}{ Others } & $46.82 \pm 1.17^{b}$ \\
\hline Benzaldehyde & $2.75 \pm 0.21^{b}$ & $4.99 \pm 0.07^{\mathrm{ab}}$ & $4.20 \pm 0.15^{b}$ & $3.57 \pm 0.04^{b}$ & $3.47 \pm 0.05^{b}$ & $4.67 \pm 0.06^{\mathrm{ab}}$ \\
\hline Phenylacetaldehyde & $2.14 \pm 0.05^{b}$ & $5.39 \pm 0.16^{\mathrm{a}}$ & $4.80 \pm 0.04^{\mathrm{a}}$ & $5.55 \pm 0.18^{a}$ & $4.73 \pm 0.08^{a}$ & $3.80 \pm 0.21 \mathrm{ab}$ \\
\hline 16-octadecenal & $1.63 \pm 0.23$ & N.D. & N.D. & N.D. & N.D. & N.D. \\
\hline Ethyl benzaldehyde & $25.42 \pm 0.91^{\mathrm{a}}$ & $11.71 \pm 1.03^{b}$ & $12.17 \pm 0.67^{b}$ & $10.21 \pm 0.12^{b}$ & $10.66 \pm 0.30^{b}$ & $8.49 \pm 0.08^{b}$ \\
\hline Curcumene & $4.63 \pm 0.10^{\mathrm{a}}$ & $5.10 \pm 0.07^{\mathrm{a}}$ & N.D. & $5.50 \pm 0.58^{a}$ & $4.30 \pm 0.09^{a}$ & $6.15 \pm 0.18^{a}$ \\
\hline Cyclohexene & $31.26 \pm 1.21^{\mathrm{a}}$ & N.D. & N.D. & $16.76 \pm 0.20^{b}$ & N.D. & N.D. \\
\hline 2,4-Di-tert-butylphenol & $7.26 \pm 0.05^{b}$ & $8.11 \pm 0.14^{b}$ & $9.23 \pm 0.13^{b}$ & $6.35 \pm 0.11^{b}$ & $7.54 \pm 0.01^{b}$ & $5.82 \pm 0.07^{b}$ \\
\hline
\end{tabular}

N.D. means no detection. Different letters indicate the significant differences at $p<0.05$.

The higher alcohols were the main group of alcohol compounds in this study. Normally, the concentration of $300-400 \mathrm{mg} / \mathrm{L}$ is acceptable, and the optimal level gives a pleasant character [27]. It could be found that phenylethyl alcohol, contributing to "rose" and "sweet" notes for wine, distributed highest in all groups, and its content was improved greatly by yeast metabolism during fermentation. There was no significant difference between FS and FS mixed, but the content of phenylethyl alcohol in YT and HL mixed was higher than corresponding single groups, thus adding more floral flavors to mixed fermented wine. The amount of $\beta$-bisabolol was higher in FS36 and FS mixed groups; farnesol, bringing the wine with floral and greenwood flavor, was only detected in single FS36 and YT28.

Oxidation-related aldehydes with low sensory thresholds and apple-like odors are important to wine aroma, making wine smell fresher [28]. Four aldehydes were identified in this study. They were benzaldehyde, phenyl acetaldehyde, 16-octadecenal, and ethyl benzaldehyde. Compared with Marselan must, the types and content of aldehydes in wine dropped distinctly as the result of chemical reactions such as oxidation/reduction, enzymatic hydrolysis, or participating in yeast bio-metabolism to form new aroma compounds. Phenyl acetaldehyde, generating floral and honey odor in wine, was highest in YT28, lowest in FS36.

Norisoprenes and its derivatives usually have apple, raspberry, papaya, violet, and other floral and fruity features, with very low threshold, and have attracted much attention in wine aroma researches. $\beta$-Damascenone is a typical substance of $C_{13}$-norisoprene family, contributing lovely characteristics of apple, rose, and honey to wine [26]. The highest value was obtained in HL mixed; moreover, the concentration of each mixed-strain group was much higher than that of the corresponding single-strain groups, responsible for giving 
more sweety and floral flavors to the wine. Except for the major aroma compounds, a small amount of olefinic substances were also detected in Marselan must and wine. Among them, cyclohexene with the value of 31.26 and 16.76 was only detected in FS groups (single and mixed). Calamenene, as one of the most typical aromas in the Marselan grape, was detected only in YT mixed and HL mixed (latter was significantly higher than the former), indicating that HL mixed could preserve more varietal characteristics. All these results indicated that the aromatic profiles of single and mixed fermentation methods varied a lot, and the inoculation with non-Saccharomyces relatively retained more Marselan features.

\subsection{Comparison of Aroma Compounds between Marselan Must and Wine}

Compared with must, the relative content of phenethyl alcohol (50-100-fold change), ethyl caprylate (480-670-fold change), and ethyl caproate (10-20-fold change) was much higher in wine (Figure 2). These aromas were produced by yeasts during wine fermentation. However, some feature aromas of Marselan such as calamenene, only increased in HL mixed; $\beta$-damascenone reduced more than $80 \%$ in all groups; benzaldehyde diminished $54.26 \%, 16.92 \%$, and $22.23 \%$ in FS36, YT28, and HL mixed, respectively (Tables 3 and 4); 2,4-di-tert-butylphenol dropped $68-81 \%$ in each group. In general, FS36 and FS mixed were worse on preserving characteristic aroma compounds, indicating that FS36 and FS mixed possibly were not capable of shaping the individual quality for Marselan wine. Esters were the main compound produced during fermentation, of which FS36 produced the most, yet HL mixed produced the least. FS36 also produced the most of new alcohols. Other fermentative aroma compounds included acids, aldehydes, etc., with a relatively minor effect on the wine, of which FS groups produced the most, followed by YT and HL groups. In conclusion, FS groups produced the most content of aromas in wine, followed by YT and HL groups. However, YT and HL groups were more capable of maintaining Marselan varietal characters such as calamenene and $\beta$-damascone.
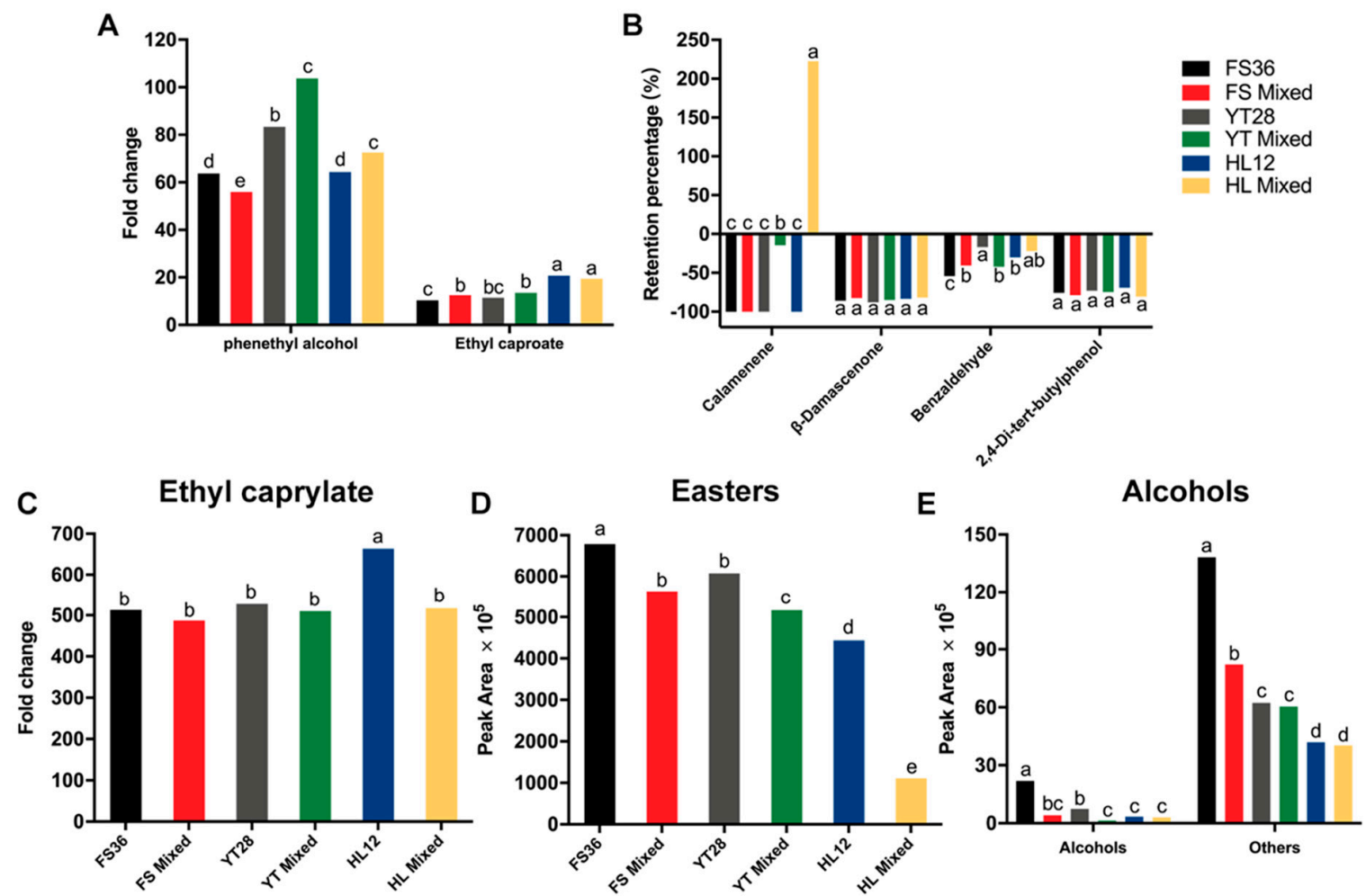

Figure 2. Changes of characteristic aromas in Marselan wine. Different letters indicate the significant differences at $p<0.05$. (A,C) The fold change of phenethyl alcohol, ethyl caproate and ethyl caprylate in Marselan wines in comparison of must, respectively; (B) The retention percentage (\%) of four varietal aromas in Marselan wines in comparison of must; (D) The peak area of easters of Marselan wines; (E) The peak area of alcohols of Marselan wines. 


\subsection{The PCA Analysis of Marselan Wine}

The composition and abundance of aroma compounds in six groups were subjected to PCA analysis and explained $71.3 \%$ of the variability in the first two dimensions. Eight characteristic Marselan varieties and six newly produced aroma compounds were used to analyze. Figure 3 depicted that PCA1 accounted for the $43.0 \%$ and PCA2 for an additional $28.0 \%$ of the variability, which clearly separated single-strain groups from mixed-strain groups, proving that different fermentation methods had dissimilarity during the aromatic compound formation, the inoculation of non-Saccharomyces indeed changed the whole quality of wine aromas. Overall, characteristic variety aromas were preserved better in the mixed-strain groups, implying that mixed-strain fermentation was a better way to retain variety features. Reversely, single-strain groups were capable of producing new fermentative aroma compounds. Interestingly, HL mixed (with apparent benzaldehyde and $\beta$-damascenone) was located in a single quadrant, implying that the features of this group were totally diverse with others; obviously, fermentative aromas of this group were less than other groups. Ethyl octoate, ethyl 9-decanoate, and decyl alcohol coming from the fermentation process were mainly centralized on the quadrant of single-strain groups.

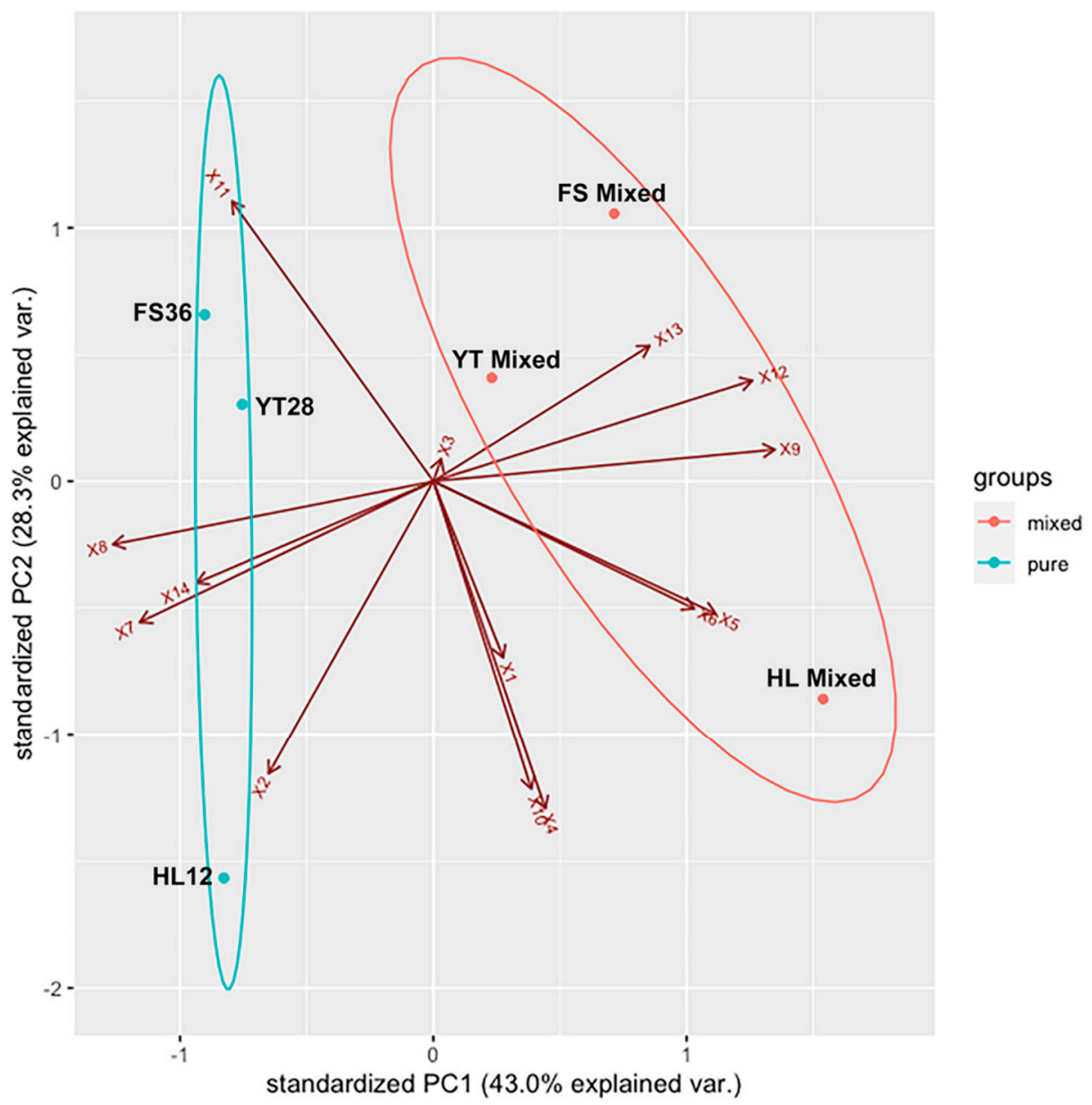

Figure 3. Principal Component Analysis (PCA) biplots of selected volatiles in six Marselan wines. (Notes X1: Benzaldehyde X2: Ethyl caprylate X3: Phenethyl alcohol X4: Ethyl caproate X5: Calamenene X6: $\beta$-Damascenone X7: 2,4-Di-tert-butylphenol X8: Phenethyl acetate X9: Hexyl acetate X10: Diethyl succinate X11: Ethyl caprate X12: Ethyl propionate X13: Trans $\beta$-farnesol X14: Decyl alcohol).

\subsection{The Sensory Analysis of Marselan Wine}

Eight aroma attributes, namely, ethanol, floral, citrus, stone fruits, berries, dry fruits, herbs, and fermentative aromas, contributed to the aroma profile of the wine. Figure 4 
demonstrated the mean scores of the sensory attributes of wines. Fermentative, ethanol, and floral attributes, mostly produced during the fermentation process, were the dominating descriptors in single-strain groups. Apparently, HL mixed had the most intense attributes of citrus, herbs, berries, and dry fruits, implying that HL mixed group had a stronger and more complicated aroma profile than other groups. FS36 has the strongest fermentative flavor but a weaker perception of other attributes. On the whole, mixed-strain groups showed stronger notes of citrus, berries, and herbs, of which HL mixed had the highest scores in both terms. Thus, HL mixed showed the most promising potential to preserve Marselan varietal and also the richest sensation among all groups.

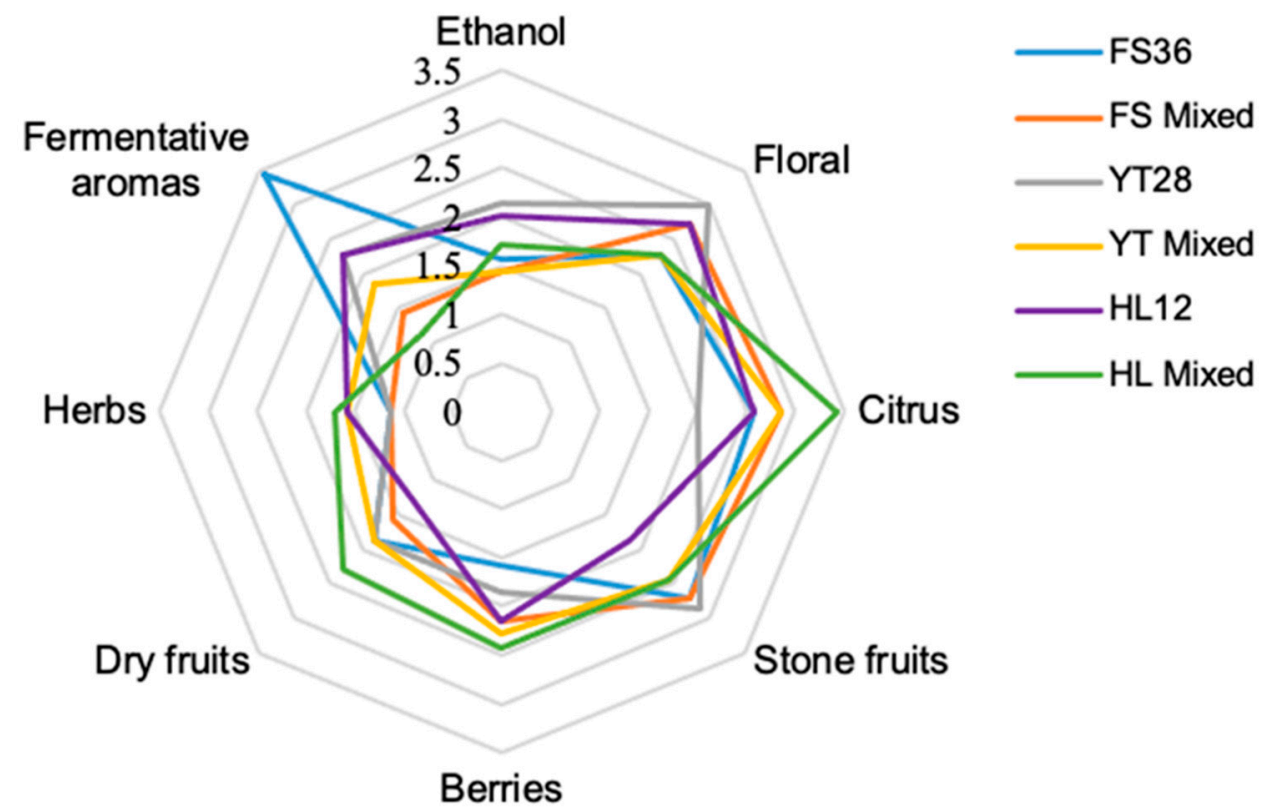

Figure 4. Radar plots of sensory evaluation of six Marselan wines.

In the PLSR model, 14 key aroma compounds were specified as the X-matrix, and the sensory attributes were specified as the Y-matrix. The correlation loading plot was shown in Figure 5. For the HL12, dried fruits, floral and alcoholic attributes were found to be associated with any of the key aroma compounds: specifically, with ethyl caprylate, $\beta$ damascenone, ethyl caproate, and diethyl succinate. For the HL mixed, strong correlations with aroma compounds were found for the citrus attribute. This was consistent with the sensory evaluations that HL mixed had the highest scores for citrus attribute, implying that citrus odor could be the characteristic sensory evaluation for HL mixed. The citrus attribute was correlated with several key aroma compounds, including benzaldehyde, trans- $\beta$ farnesol, ethyl propionate, hexyl acetate, and calamenene. For the FS36 and FS mixed, fermentation aromas and berries were the main attributes that correlated with the aroma compounds such as decyl alcohol, 2,4-di-tertbutyl phenol, and phenethyl acetate. For YT28 and YT mixed, both were related to phenethyl alcohol, but there was no related attribute. 
A



B



Figure 5. Partial least square regression correlation plot for six Marselan wines. The model was established by 14 key aroma compounds of GC-MS measurements as X, Y for the flavor attributes. (A) Scores of samples; (B) correlation loadings of $\mathrm{X}$ and $\mathrm{Y}$.

\section{Discussion}

Aroma compounds are secondary metabolites that play an essential role in grape quality for enological purposes. Grape aromas were mostly coming from sugar. Many factors, including biotic and abiotic types, can influence the biosynthesis of aroma compounds in grape fruits, such as grape maturity, geographical locations, climates, and agronomic practice [29-31]. To the best of our knowledge, we were the first team to analyze the varietal aroma of Marselan grape must. Totally, there were 42 kinds of aromas identified, of which 2018 YT had the most. Three samples coming from the 2018 vintage had more types of aromas than the 2017 sample, probably due to its younger vintage. As wine ages, chemicals such as oxidation and reduction reactions will happen, and aging aromas will arise, but varietal aromas will decline. Compounds forming primary aromas belong to a limited number of chemical families, including methoxypyrazines, $\mathrm{C}_{13}$-norisoprenoids, volatile sulfur compounds, and terpenes [32]. Twenty kinds of aromas were detected in common, and five of them (calamenene, $\beta$-damascenone, $n$-hexanal, furfural, and ceremonene) were significant among samples. $\beta$-ionone and $\beta$-damascenone are the main $\mathrm{C}_{13}$-norisoprenoids compounds derived from carotenoids detected much in non-floral grapes. Terpenoids mostly existed in aromatic varieties such as Muscat, Gewürztraminer, and Rhine Riesling [33]. Particularly, five monoterpenoid alcohols, namely linalool, geraniol, nerol, citronellol, and $\alpha$-terpineol, are the most abundant and the strongest contributors to wine aroma with floral sense and low odor thresholds [34]. Compared with other kinds of aromas, the concentrations of terpenes and $\mathrm{C}_{13}$-norisoprenoids were much lower (Table 3), and our results were consistent with other studies [35-37].

It has been uncovered that phenols, terpenes, $\mathrm{C}_{13}$-norisoprenoids, and non-terpenic alcohols are the most important aroma substances in grapes, and they can be detected as free volatiles or glycol-conjugated molecules, of which the non-volatile glycosylated group contributes the largest and presents in all varieties of Vitis vinifera. However, only volatile 
groups can be detected by GC-MS, so there still remains many aroma compounds that cannot be captured in the must. These important aroma precursors are linked to sugar molecules, mainly terpenol and $\mathrm{C}_{13}$-norisoprenoid glycosides. Free styles could be released by hydrolysis during fermentation through the bioactivities of yeasts. There are two enzymes that existed in yeasts involving in aroma release, one is glycosidases, hydrolyzing the non-volatile glycosidic precursors, and the other is carbon-sulfur lyases, releasing volatile thiols from aroma-inactive cysteine-bound conjugates [38]. Even though all samples coming from the same region and vintage, the influences of agronomic practices cannot be excluded, such as irrigation, training systems, leaf removal, and bunch thinning [39]. Usually, agronomic practices do not always have uniform results, and each viticulturist has a distinct personal pattern; therefore, the metabolic and physiological changes resulting from agronomic practices were unknown. Furthermore, 20 characteristic aromas were found in common in all must samples, relatively representing the varietal aromas of the Marselan grape.

Marselan is one of the most popular grape varieties planted in China in recent years. The Marselan wine fermented by commercial Saccharomyces yeasts usually has a monotonous taste, lacking the varietal vigor and geographical characteristics. Conversely, indigenous wild yeasts are exhibiting more and more diversity and suitable brewing potential. However, limited studies have been carried out to improve its enological characteristics through the use of indigenous wine yeasts. Nowadays, the use of nonSaccharomyces yeasts co-inoculated with Saccharomyces cerevisiae is a popular strategy to improve the diversity and quality of wine aroma. The design of starters, including selected non-Saccharomyces yeasts with optimized biotechnological characteristics, has become one of the main challenges for researchers and oenologists. In this study, the effect of indigenous non-Saccharomyces inoculated with matched indigenous $S$. cerevisiae strains on aroma quality was investigated, with the aim to evaluate whether multiculture of specific non-Saccharomyces with local S. cerevisiae strains could produce high diversified aromatic quality. Naturally, Saccharomyces yeasts have a better ability to complete fermentation than non-Saccharomyces yeasts due to their adaptative genes to transform sugar and high tolerance of alcohol [40]. Consistent with above, all single-strain groups in our results fermented faster, which was in agreement with numerous studies [7,41-46]. FS36 was the fastest, implying that this strain has the best fermentation ability, followed by HL12 and YT28. There is a concern wherein the initial growth of non-Saccharomyces may be stuck or sluggish fermentations or reduce the production of detrimental compounds to the sensory properties of wine [47]. Like many successful non-Saccharomyces isolates, the selected non-Saccharomyces yeasts in our experiments did not suspend or affect the fermentation process, so these strains were well qualified to be used as starters [48-51]. All the groups showed suitable fermentation kinetics, implying that they have great potential to be used in industrial production.

Glycerol is one important product of yeast fermentation and is typically found at concentrations of $4-10 \mathrm{~g} / \mathrm{L}$ in dry wine. In general, higher glycerol levels are considered to improve wine quality, contributing to smoothness, sweetness, and complexity for wines. From our results, except for FS36, mixed-strain groups produced more glycerol than singlestrain groups. Previous studies discovered that wine fermented with non-Saccharomyces yeasts produced higher glycerol concentrations during alcoholic fermentation, which was in accordance with our results [8,52-54]. Generally, increased glycerol together with reduced alcohol in mixed fermentation has been observed in many research. The main reason is that some non-Saccharomyces cerevisiae is able to convert part of the carbon flux from the way of synthesizing alcohol to glycerol due to gene mutation or natural selection. However, from Table S1, the content of alcohol in three mixed-strain groups was not statistically significant from that of the single-strain groups, and there was even a slight increase trend, which was inconsistent with the above theory. In fact, many factors could affect the synthesis of alcohol or glycerol because numerous metabolic behaviors occur at the same time, although their carbon source all derives from sugar, the product of photosynthesis. For one thing, there is 
no absolute negative relation between the synthesis of glycerol and alcohol. For instance, the hybrid yeasts from $S$. cerevisiae $\times$ S. uvarum increased glycerol production compared to the S. cerevisiae parent; however, no reduction in ethanol concentration was observed [55]. Glycerol production in Saccharomyces cerevisiae can be induced by the addition of sulfite to the growth medium, which cannot be used for ethanol production due to the combination of sulfite and acetaldehyde. Thus, another study used sulfite to select yeasts with suitable adaption of high osmotic pressure, and this method successfully led to finding the yeasts that resulted in a $46 \%$ increase in glycerol yield. However, ethanol production was just a minor decrease [56]. For another, the production of glycerol largely depends on the redox balance within yeast cells, and both osmotic pressure and fermentation temperature can influence its content. In addition to alcohol, the synthesis rate of glycerol is widely adjusted by some metabolites such as organic acids, which can alter redox balance and/or influence yeast metabolism [56]. From Table S1, it could be found that the level of organic acids in the mixed group was lower (such as acetic acid, tartaric acid, and citric acid) than single ones, which partly explained why the alcohol content was not reduced because fractional carbon flux for organic acids has been transferred to the synthesis branches of alcohol, which further regulate the redox balance in the whole environment. Therefore, it is not credible to deduce the content of any one according to the other content. Furthermore, non-Saccharomyces yeasts have the ability to redirect the sugar consumption to produce alternative compounds, such as glycerol, with no apparent harm to wine or pyruvic acid produced via glycerol-pyruvic metabolisms. In conclusion, the inoculation with nonSaccharomyces yeasts as co-starters could be a promising technology to enhance the wine taste and final quality.

Previously, Lyu et al. identified several key aromas such as $\beta$-damascenone, eugenol, and 2,3-butanedione in Marselan wine, and found a suitable similarity of blackberry, green pepper, honey, raspberry, caramel, smoky, and cinnamon aroma attributes between the original Marselan wine and the reconstructed wine [20]. In this study, there were 53 aroma compounds detected in total, containing esters, higher alcohols, aldehydes, and norisoprenes. Esters are the most abundant compounds found in this study. Compared with the must, esters in wine were greatly improved due to the yeast metabolic activities. Ethyl decanoate was the single most abundant ester in all samples, associated with fruity and floral aromas [57]. Although esters provide wine with pleasant flavors, to preserve the varietal characteristics from the grape, the production of esters at proper concentrations is important to avoid masking the grape varietal aromas. The co-inoculation with some nonSaccharomyces yeast is an efficient way to produce wine with lower esters than Saccharomyces only. It has been found that the use of M. pulcherrima (a non-Saccharomyces) reduced the final total ester yield by approximately 33\% [58]. Our results showed that the amount of esters in mixed-strain groups were lower than in single-strain groups, suggesting that the selected non-Saccharomyces reduced the easter aromas (Table S2). $\beta$-Damascenone is a typical substance of the $\mathrm{C}_{13}$-norisoprene family, associated with apple, rose, and honey flavors [26]. The highest value was obtained in HL mixed; moreover, the concentration of $\beta$ damascenone in each mixed-strain group was much higher than that of the corresponding single-strain groups, implying that mixed fermentation was better to preserve the varietal aroma characteristics. Calamenene was another important aroma of Marselan must, which was also kept better in mixed groups. Actually, the promotion of flowery and fruity aromas by mixed fermentation with non-Saccharomyces have been confirmed by many studies. Zhang et al. used indigenous Torulaspora delbrueckii (TD12) co-fermented with Saccharomyces and found the mixed fermentation achieved higher aroma diversity, and generate higher intensity of fruity, flowery and sweet attributes of wine [59]. Another selected Hanseniaspora uvarum (H. uvarum) Yun268 (non-Saccharomyces) was found to improve the concentration of aromatic compounds via high levels of $\beta$-glucosidase activity and fatty acids [60]. The application of indigenous non-Saccharomyces Hanseniaspora vineae and Metschnikowia pulcherrima co-fermentation with Saccharomyces cerevisiae improved the aroma diversity in Vidal blanc ice wine [61]. Tristezza et al. used a local S. cerevisiae co-fermented with three $H$. 
uvarum and found that $H$. uvarum contributed to increasing the wine organoleptic quality and simultaneously reducing the volatile acidity [61]. In addition, many studies came to similar conclusions [42,44-46,60,62]. These results explicated that mixed fermentation have more advantages than single fermentation.

Generally, there are two practices when using non-Saccharomyces yeasts in mixed fermentation. One is co-inoculation, the other is sequential inoculation. When fermentations are conducted with more than one yeast, complex interactions between organisms will happen. Both methods are feasible, although potential interactions between yeasts could determine which inoculation strategy is more appropriate. In this study, all groups were treated with sequential inoculation. Therefore, co-inoculation should be investigated further to figure out which method is better to improve aromas in Marselan wine. Interestingly, a study investigated both methods with Torulaspora delbrueckii and found sequential inoculation achieved higher aroma diversity than co-inoculation. The possible mechanism was the inhibitory effects on the growth of non-Saccharomyces in the initial fermentation [59]. Importantly, the composition, interaction, and diversity of the yeast micro-population significantly contribute to the sensory characteristics of wine, so more research needs to be performed to elucidate the relations between yeasts and final aromas. In this paper, we did not carry out the commercial fermentation trials because the main purpose of this study was to compare and explore the single or mixed fermentation started by indigenous Saccharomyces or non-Saccharomyces yeasts to figure out the effects on the aroma formation in Marselan wine. We hope to provide a theoretical basis for the industrial application of these promising yeasts. From the sensory analysis, it could be found that the features and uniqueness of the Marselan grape were most highlighted by HL mixed with the must from the same place. Previous studies have shown that the yeast populations have been found to be regionally distinct, a concept coined microbial terroir, which suggests that the certain aroma fingerprints formed between grapes and the environment are likely to be based on specific microbial populations, especially non-Saccharomyces cerevisiae. So indigenous yeasts from the same region as grape variety possibly are more conducive to preserve local variety characteristics than the yeasts from other areas.

Taken together, our results suggest that the wild indigenous yeasts from the same region as grape variety are possibly in favor of preserving varietal characteristics in wine, especially the mixed fermentation with non-Saccharomycetes, probably due to its better adaptability of local climate and geography, which could be applied as a clue to make personalized wine with outstanding characteristics.

\section{Conclusions}

Three autochthonous Saccharomyces yeasts had the excellent ability of fermentation, and the inoculation of matched non-Saccharomyces did not suspend or hinder the whole process. The sequential inoculation of non-Saccharomyces kept the varietal sensation better than single Saccharomyces, both in chemical compounds and sensory evaluation. HL mixed had the best performance to preserve Marselan grape features such as citrus, berries, dry fruits, and herbs characters, also with the least tedious fermentative flavors. Our study implies that the indigenous yeasts from the same region as the grape variety seem more conducive to preserve local variety characteristics.

Supplementary Materials: The following are available online at https:/ / www.mdpi.com/article/10 .3390 / fermentation7030133/s1. Figure S1: The relative content of characteristic aroma compounds in Maeselan must. Table S1: The results of physicochenmical indexes of Marselan must and wine. Table S2: Summary of the volatile aroma components of Marselan wine.

Author Contributions: X.X.: Methodology, Formal analysis, Project administration, Writing-review and editing. A.X.: Methodology, Formal analysis, Project administration. Y.Y.: Investigation, Formal analysis, Funding acquisition, Writing—review and editing. W.H.: Conceptualization, Writingreview and editing, Funding acquisition. J.Z.: Conceptualization, Writing-review and editing, Supervision, Funding acquisition. All authors have read and agreed to the published version of the manuscript. 
Funding: This work was supported by the National "Thirteenth Five-Year" Plan for Science and Technology Support (2016YFD0400500).

Institutional Review Board Statement: Not applicable.

Informed Consent Statement: Not applicable.

Data Availability Statement: Not applicable.

Acknowledgments: We genuinely thank programmer Shuai Peng for the PCA coding with R Studio software.

Conflicts of Interest: The authors declare no conflict of interest.

\section{References}

1. Styger, G.; Prior, B.; Bauer, F.F. Wine flavor and aroma. J. Ind. Microbiol. Biotechnol. 2011, 38, 1145-1159. [CrossRef]

2. Van Wyk, N.; Grossmann, M.; Wendland, J.; Von Wallbrunn, C.; Pretorius, I.S. The Whiff of Wine Yeast Innovation: Strategies for Enhancing Aroma Production by Yeast during Wine Fermentation. J. Agric. Food Chem. 2019, 67, 13496-13505. [CrossRef]

3. Borren, E.; Tian, B. The Important Contribution of Non-Saccharomyces Yeasts to the Aroma Complexity of Wine: A Review. Foods 2021, 10, 13. [CrossRef]

4. Alperstein, L.; Gardner, J.M.; Sundstrom, J.F.; Sumby, K.M.; Jiranek, V. Yeast bioprospecting versus synthetic biology-Which is better for innovative beverage fermentation? Appl. Microbiol. Biotechnol. 2020, 104, 1-15. [CrossRef]

5. Meier-Dörnberg, T.; Kory, O.I.; Jacob, F.; Michel, M.; Hutzler, M. Saccharomyces cerevisiae variety diastaticus friend or foe? Spoilage potential and brewing ability of different Saccharomyces cerevisiae variety diastaticus yeast isolates by genetic, phenotypic and physiological characterization. FEMS Yeast Res. 2018, 18, foy023. [CrossRef] [PubMed]

6. Lin, M.M.-H.; Boss, P.K.; Walker, M.E.; Sumby, K.M.; Grbin, P.R.; Jiranek, V. Evaluation of indigenous Non-Saccharomyces yeasts isolated from a South Australian vineyard for their potential as wine starter cultures. Int. J. Food Microbiol. 2020, $312,108373$. [CrossRef] [PubMed]

7. Binati, R.L.; Lemos, J.W.J.; Luzzini, G.; Slaghenaufi, D.; Ugliano, M.; Torriani, S. Contribution of Non-Saccharomyces yeasts to wine volatile and sensory diversity: A study on Lachancea thermotolerans, Metschnikowia spp. and Starmerella bacillaris strains isolated in Italy. Int. J. Food Microbiol. 2020, 318, 108470. [CrossRef]

8. Escribano-Viana, R.; González-Arenzana, L.; Portu, J.; Garijo, P.; López-Alfaro, I.; López, R.; Santamaría, P.; Gutiérrez, A.R. Wine aroma evolution throughout alcoholic fermentation sequentially inoculated with Non-Saccharomyces/Saccharomyces yeasts. Food Res. Int. 2018, 112, 17-24. [CrossRef] [PubMed]

9. Liu, P.-T.; Lu, L.; Duan, C.-Q.; Yan, G.-L. The contribution of indigenous Non-Saccharomyces wine yeast to improved aromatic quality of Cabernet Sauvignon wines by spontaneous fermentation. LWT 2016, 71, 356-363. [CrossRef]

10. Morata, A.; Escott, C.; Bañuelos, M.A.; Loira, I.; Del Fresno, J.M.; González, C.; Suárez-lepe, J.A. Contribution of NonSaccharomyces yeasts to wine freshness. A review. Biomolecules 2020, 10, 34. [CrossRef]

11. Jolly, N.P.; Varela, C.; Pretorius, I.S. Not your ordinary yeast: Non-Saccharomyces yeasts in wine production uncovered. FEMS Yeast Res. 2014, 14, 215-237. [CrossRef] [PubMed]

12. Comitini, F.; Gobbi, M.; Domizio, P.; Romani, C.; Lencioni, L.; Mannazzu, I.; Ciani, M. Selected Non-Saccharomyces wine yeasts in controlled multistarter fermentations with Saccharomyces cerevisiae. Food Microbiol. 2011, 28, 873-882. [CrossRef] [PubMed]

13. Petruzzi, L.; Capozzi, V.; Berbegal, C.; Corbo, M.R.; Bevilacqua, A.; Spano, G.; Sinigaglia, M. Microbial Resources and Enological Significance: Opportunities and Benefits. Front. Microbiol. 2017, 8, 995. [CrossRef]

14. Chen, K.; Escott, C.; Loira, I.; del Fresno, J.M.; Morata, A.; Tesfaye, W.; Calderon, F.; Suárez-Lepe, J.A.; Han, S.; Benito, S. Use of Non-Saccharomyces yeasts and oenological tannin in red winemaking: Influence on colour, aroma and sensorial properties of young wines. Food Microbiol. 2018, 69, 51-63. [CrossRef] [PubMed]

15. Carrau, F.M.; Rivas-Gonzalo, J.C.; Alcalde-eon, C.; Boido, E.; Dellacassa, E. Pigment Profiles in Monovarietal Wines Produced in Uruguay. Am. J. Enol. Vitic. 2006, 57, 449-459.

16. Robinson, J.; Harding, J.; Vouillamoz, J. Wine Grapes: A Complete Guide to 1368 Vine Varieties, Including Their Origins and Flavours; Penguin: London, UK, 2013.

17. Sagratini, G.; Maggi, F.; Caprioli, G.; Cristalli, G.; Ricciutelli, M.; Torregiani, E.; Vittori, S. Comparative study of aroma profile and phenolic content of Montepulciano monovarietal red wines from the Marches and Abruzzo regions of Italy using HS-SPME-GCMS and HPLC-MS. Food Chem. 2012, 132, 1592-1599. [CrossRef] [PubMed]

18. Suzzi, G.; Arfelli, G.; Schirone, M.; Corsetti, A.; Perpetuini, G.; Tofalo, R. Effect of grape indigenous Saccharomyces cerevisiae strains on Montepulciano d'Abruzzo red wine quality. Food Res. Int. 2012, 46, 22-29. [CrossRef]

19. Sun, Y.; Li, E.; Qi, X.; Liu, Y. Changes of diversity and population of yeasts during the fermentations by pure and mixed inoculation of Saccharomyces cerevisiae strains. Ann. Microbiol. 2015, 65, 911-919. [CrossRef]

20. Lyu, J.; Ma, Y.; Xu, Y.; Nie, Y.; Tang, K. Characterization of the Key Aroma Compounds in Marselan Wine by Gas ChromatographyOlfactometry, Quantitative Measurements, Aroma Recombination, and Omission Tests. Molecules 2019, 24, 2978. [CrossRef] 
21. Conde, C.; Agasse, A.; Glissant, D.; Tavares, R.; Gerós, H.; Delrot, S. Pathways of Glucose Regulation of Monosaccharide Transport in Grape Cells. Plant Physiol. 2006, 141, 1563-1577. [CrossRef]

22. Tronchoni, J.; Gamero, A.; Arroyo-López, F.N.; Barrio, E.; Querol, A. Differences in the glucose and fructose consumption profiles in diverse Saccharomyces wine species and their hybrids during grape juice fermentation. Int. J. Food Microbiol. 2009, 134, $237-243$. [CrossRef] [PubMed]

23. Loureiro, V.; Malfeito-Ferreira, M. Spoilage yeasts in the wine industry. Int. J. Food Microbiol. 2003, 86, 23-50. [CrossRef]

24. Kelebek, H.; Kesen, S.; Sonmezdag, A.S.; Cetiner, B.; Kola, O.; Selli, S. Characterization of the key aroma compounds in tomato pastes as affected by hot and cold break process. J. Food Meas. Charact. 2018, 12, 2461-2474. [CrossRef]

25. Comuzzo, P.; Tat, L.; Tonizzo, A.; Battistutta, F. Yeast derivatives (extracts and autolysates) in winemaking: Release of volatile compounds and effects on wine aroma volatility. Food Chem. 2006, 99, 217-230. [CrossRef]

26. González-Barreiro, C.; Rial-Otero, R.; Cancho-Grande, B.; Simal-Gándara, J. Wine Aroma Compounds in Grapes: A Critical Review. Crit. Rev. Food Sci. Nutr. 2015, 55, 202-218. [CrossRef] [PubMed]

27. Rapp, A.; Versini, G. Influence of nitrogen compounds in grapes on aroma compounds of wines. Dev. Food Sci. 1995, 37, 1659-1694. [CrossRef]

28. Culleré, L.; Cacho, J.; Ferreira, V. An assessment of the role played by some oxidation-related aldehydes in wine aroma. J. Agric. Food Chem. 2007, 55, 876-881. [CrossRef]

29. Spayd, S.E.; Tarara, J.M.; Mee, D.L.; Ferguson, J.C. Separation of sunlight and temperature effects on the composition of Vitis vinifera cv. Merlot berries. Am. J. Enol. Vitic. 2002, 53, 171-182. [CrossRef]

30. Hernández-Orte, P.; Cersosimo, M.; Loscos, N.; Cacho, J.; Garcia-Moruno, E.; Ferreira, V. The development of varietal aroma from non-floral grapes by yeasts of different genera. Food Chem. 2008, 107, 1064-1077. [CrossRef]

31. Ewart, A.; Brien, C.; Soderlund, R.; Smart, R. The effects of light pruning, irrigation and improved soil management on wine quality of the Vitis vinifera cv. Riesling. Vitis Geilweilerhof. 1985, 24, 209-217.

32. Ebeler, S.E.; Thorngate, J.H. Wine chemistry and flavor: Looking into the crystal glass. J. Agric. Food Chem. 2009, 57, 8098-8108. [CrossRef]

33. King, A.; Dickinson, J.R. Biotransformation of monoterpene alcohols by Saccharomyces cerevisiae, Torulaspora delbrueckii and Kluyveromyces lactis. Yeast 2000, 16, 499-506. [CrossRef]

34. Mateo, J.J.; Jiménez, M. Monoterpenes in grape juice and wines. J. Chromatogr. A 2000, 881, 557-567. [CrossRef]

35. Pogorzelski, E.; Wilkowska, A. Flavour enhancement through the enzymatic hydrolysis of glycosidic aroma precursors in juices and wine beverages: A review. Flavour Fragr. J. 2010, 22, 251-254. [CrossRef]

36. Liang, Z.; Fang, Z.; Pai, A.; Luo, J.; Gan, R.; Gao, Y.; Lu, J.; Zhang, P. Glycosidically bound aroma precursors in fruits: A comprehensive review. Crit. Rev. Food Sci. Nutr. 2020, 1-29. [CrossRef]

37. Yang, Y.; Jin, G.-J.; Wang, X.-J.; Kong, C.-L.; Liu, J.; Tao, Y.-S. Chemical profiles and aroma contribution of terpene compounds in Meili (Vitis vinifera L.) grape and wine. Food Chem. 2019, 284, 155-161. [CrossRef]

38. Holt, S.; Miks, M.H.; De Carvalho, B.T.; Foulquié-Moreno, M.R.; Thevelein, J.M. The molecular biology of fruity and floral aromas in beer and other alcoholic beverages. FEMS Microbiol. Rev. 2019, 43, 193-222. [CrossRef] [PubMed]

39. Alem, H.; Rigou, P.; Schneider, R.; Ojeda, H.; Torregrosa, L. Impact of agronomic practices on grape aroma composition: A review. J. Sci. Food Agric. 2019, 99, 975-985. [CrossRef] [PubMed]

40. Padilla, B.; Gil, J.V.; Manzanares, P. Past and Future of Non-Saccharomyces Yeasts: From Spoilage Microorganisms to Biotechnological Tools for Improving Wine Aroma Complexity. Front. Microbiol. 2016, 7, 411. [CrossRef]

41. Padilla, B.; Zulian, L.; Ferreres, À.; Pastor, R.; Esteve-zarzoso, B.; Beltran, G.; Mas, A. Sequential Inoculation of Native NonSaccharomyces and Saccharomyces cerevisiae Strains for Wine Making. Front. Microbiol. 2017, 8, 1293. [CrossRef]

42. Renault, P.; Coulon, J.; de Revel, G.; Barbe, J.C.; Bely, M. Increase of fruity aroma during mixed T. delbrueckii/S. cerevisiae wine fermentation is linked to specific esters enhancement. Int. J. Food Microbiol. 2015, 207, 40-48. [CrossRef]

43. Tofalo, R.; Patrignani, F.; Lanciotti, R.; Perpetuini, G.; Schirone, M.; Di Gianvito, P.; Pizzoni, D.; Arfelli, G.; Suzzi, G. Aroma profile of montepulciano d'abruzzo wine fermented by single and co-culture starters of autochthonous Saccharomyces and Non-Saccharomyces yeasts. Front. Microbiol. 2016, 7, 610. [CrossRef]

44. Medina, K.; Boido, E.; Fariña, L.; Gioia, O.; Gomez, M.E.; Barquet, M.; Gaggero, C.; Dellacassa, E.; Carrau, F. Increased flavour diversity of Chardonnay wines by spontaneous fermentation and co-fermentation with Hanseniaspora vineae. Food Chem. 2013, 141, 2513-2521. [CrossRef]

45. Terrell, E.; Cliff, M.A.; Van Vuuren, H.J.J. Functional characterization of individual- and mixed-Burgundian Saccharomyces cerevisiae isolates for fermentation of pinot noir. Molecules 2015, 20, 5112-5136. [CrossRef]

46. Hu, K.; Jin, G.-J.; Mei, W.-C.; Li, T.; Tao, Y.-S. Increase of medium-chain fatty acid ethyl ester content in mixed H. uvarum/S. cerevisiae fermentation leads to wine fruity aroma enhancement. Food Chem. 2018, 15, 495-501. [CrossRef]

47. Du Toit, M.; Pretorius, I.S. Microbial Spoilage and Preservation of Wine: Using Weapons from Nature's Own Arsenal. S. Afr. J. Enol. Vitic. 2000, 21, 74-76. [CrossRef]

48. Minnaar, P.P.; Du Plessis, H.W.; Jolly, N.P.; Van Der Rijst, M.; Du Toit, M. Non-Saccharomyces yeast and lactic acid bacteria in Co-inoculated fermentations with two Saccharomyces cerevisiae yeast strains: A strategy to improve the phenolic content of Syrah wine. Food Chem. 2019, 11, 100070. [CrossRef] [PubMed] 
49. Vilela, A. Lachancea thermotolerans, the Non-Saccharomyces yeast that reduces the volatile acidity of wines. Fermentation 2018, 4 , 56. [CrossRef]

50. Ivit, N.N.; Kemp, B. The impact of Non-Saccharomyces yeast on traditional method sparkling Wine. Fermentation $2018,4,73$. [CrossRef]

51. Dutraive, O.; Benito, S.; Fritsch, S.; Beisert, B.; Patz, C.-D.; Rauhut, D. Effect of sequential inoculation with Non-Saccharomyces and Saccharomyces yeasts on Riesling wine chemical composition. Fermentation 2019, 5, 79. [CrossRef]

52. Rantsiou, K.; Dolci, P.; Giacosa, S.; Torchio, F.; Tofalo, R.; Torriani, S.; Suzzi, G.; Rolle, L.; Cocolin, L. Candida zemplinina can reduce acetic acid produced by Saccharomyces cerevisiae in sweet wine fermentations. Appl. Environ. Microbiol. 2012, 78, 1987-1994. [CrossRef]

53. Domizio, P.; Liu, Y.; Bisson, L.F.; Barile, D. Cell wall polysaccharides released during the alcoholic fermentation by SchizoSaccharomyces pombe and S. japonicus: Quantification and characterization. Food Microbiol. 2017, 61, 136-149. [CrossRef]

54. Di Gianvito, P.; Perpetuini, G.; Tittarelli, F.; Schirone, M.; Arfelli, G.; Piva, A.; Patrignani, F.; Lanciotti, R.; Olivastri, L.; Suzzi, G. Impact of Saccharomyces cerevisiae strains on traditional sparkling wines production. Food Res. Int. 2018, 109, 552-560 [CrossRef]

55. Coloretti, F.; Zambonelli, C.; Tini, V. Characterization of flocculent Saccharomyces interspecific hybrids for the production of sparkling wines. Food Microbiol. 2006, 23, 672-676. [CrossRef]

56. Kutyna, D.R.; Varela, C.; Stanley, G.A.; Borneman, A.R.; Henschke, P.A.; Chambers, P.J. Adaptive evolution of Saccharomyces cerevisiae to generate strains with enhanced glycerol production. Appl. Microbiol. Biotechnol. 2012, 93, 1175-1184. [CrossRef]

57. Lambrechts, M.G.; Pretorius, I.S. Yeast and its Importance to Wine Aroma-A Review. S. Afr. J. Enol. Vitic. 2019, 21, 97-129. [CrossRef]

58. Benito, S.; Hofmann, T.; Laier, M.; Lochbühler, B.; Schüttler, A.; Ebert, K.; Fritsch, S.; Röcker, J.; Rauhut, D. Effect on quality and composition of Riesling wines fermented by sequential inoculation with Non-Saccharomyces and Saccharomyces cerevisiae. Eur. Food Res. Technol. 2015, 241, 707-717. [CrossRef]

59. Zhang, B.Q.; Luan, Y.; Duan, C.Q.; Yan, G.L. Use of Torulaspora delbrueckii Co-fermentation with two Saccharomyces cerevisiae Strains with different aromatic characteristic to improve the diversity of red wine aroma profile. Front. Microbiol. 2018, 5, 606. [CrossRef] [PubMed]

60. Hu, K.; Jin, G.-J.; Xu, Y.-H.; Tao, Y.-S. Wine aroma response to different participation of selected Hanseniaspora uvarum in mixed fermentation with Saccharomyces cerevisiae. Food Res. Int. 2018, 108, 119-127. [CrossRef]

61. Zhang, B.-Q.; Shen, J.-Y.; Duan, C.-Q.; Yan, G.-L. Use of indigenous Hanseniaspora vineae and Metschnikowia pulcherrima co-fermentation with Saccharomyces cerevisiae to improve the aroma diversity of Vidal Blanc icewine. Front. Microbiol. 2018, 9 , 2303. [CrossRef]

62. Gobbi, M.; Comitini, F.; Domizio, P.; Romani, C.; Lencioni, L.; Mannazzu, I.; Ciani, M. Lachancea thermotolerans and Saccharomyces cerevisiae in simultaneous and sequential co-fermentation: A strategy to enhance acidity and improve the overall quality of wine. Food Microbiol. 2013, 33, 271-281. [CrossRef] [PubMed] 